\title{
PERCEPÇÃO DE USUÁRIAS SOBRE A PRÁTICA DO ACOLHIMENTO NA COLETA DE PREVENTIVO DE CÂNCER DE COLO DE ÚTERO
}

\section{Perception of users about the practice of greeting inpreventive collection of cer vical cancer of uterus \\ Percepção de acolhimento na coleta de preventivo de câncer}

Poliana do Prado Andrade. Universidade do Planalto Catarinense - UNIPLAC; Jaqueline Aparecida Erig Omizzolo. Universidade do Planalto Catarinense UNIPLAC;

Margarete Verônica Jesse dos Santos. Universidade do Planalto Catarinense UNIPLAC;

Danielle Zanini. Universidade do Planalto Catarinense - UNIPLAC;

Endereço de correspondência:

Av. Castelo Branco, 170 - Bloco CCJ -

Setor de Pós-graduação. Bairro

Universitário, Lages, Santa Catarina,

CEP: 88.509-900.

E-mail: polipandrade@hotmail.com

\section{RESUMO}

O câncer de colo de útero tem alta taxa de mortalidade no país, considerado o quarto câncer mais comum entre mulheres no ranking nacional e apresenta o maior potencial de prevenção e cura se diagnosticado precocemente. O objetivo foi identificar a influência do acolhimento em usuárias de uma unidade básica de saúde, relacionando-o ao retorno para exame citopatológico - Papanicolaou de câncer de colo de útero. Trata-se de um estudo com abordagem qualitativa, realizado em Unidade Básica de Saúde na serra catarinense. Participaram da pesquisa onze sujeitos que atenderam aos critérios de inclusão. Os resultados apontaram que a efetivação do acolhimento depende do estabelecimento do vínculo profissionalusuário e da postura acolhedora que vai além da estrutura física, o que está ligado com os processos de trabalho. Considera-se a relação entre o acolhimento e o exame Papanicolau com laços carregados de sentimentos que acompanham as usuárias durante o exame. A compreensão de como é feito o exame, a importância do mesmo e a postura que o profissional adota durante este processo, aproxima as usuárias do serviço e estabelece uma relação de confiança, permitindo a participação destas com 
sugestões e expectativas para o exame. Conclui-se que é um desafio manter entre os profissionais uma postura acolhedora, necessitando o olhar amplo e atento dos gestores para realizar educações permanentes e qualificações sobre o tema.

Palavras-chave: Acolhimento; Exame Papanicolaou; Saúde da Família.

\section{ABSTRACT}

The cervical cancer of uterus has high mortality rate in the country, considered the fourth most common cancer among women in the national ranking and offers the greatest potencial for prevention and cure if diagnosed early. The objective was to identify the influence of host users a basic health unit in relation to the return to cytopathological examination - Pap Smear for cervical cancer of uterus. This is study with a qualitative approach, directed at basic health Unit in Serra Catarinense. Eleven participated in there search subjects who met the inclusion criteria. The results showed that the effect of the host depends on the establishment of the professional-user link and warm posture that goes beyond the physical structure, that is connected with work processes. It is considered the relationship between the host and the Pap Smear whit loaded feelings which accompany the users during the test. Understanding how the test is done, the importance of itand adopts professional stance during this process, users of the service and establishes a relationship of trust, allowing the participation of those with suggestions and expectations for the exam. It is concluded that it is a challenge to maintain a welcoming professionals, requiring large and attentive look of managers to carry out permanent upbringings and qualifications on the topic.

Keywords: greeting; Pap Smear; Family health.

\section{INTRODUÇÃO}

O tema câncer de colo do útero é algo que vem sendo discutido há alguns anos no Brasil e no mundo gerando certa preocupação aos gestores em saúde, pois afeta inúmeras mulheres, sendo um problema possível de se resolver com ações de prevenção das doenças e promoção em saúde.

Segundo o Instituto Nacional do Câncer (INCA), o conceito de câncer do colo do útero é assim entendido:

O câncer do colo do útero é caracterizado pela replicação desordenada do epitélio de revestimento do órgão, comprometendo o tecido subjacente (estroma) e podendo invadir estruturas e órgãos contíguos ou à distância. Há 
duas principais categorias de carcinomas invasores do colo do útero, dependendo da origem do epitélio comprometido: o carcinoma epidermoide, tipo mais incidente e que acomete o epitélio escamoso (representa cerca de $90 \%$ dos casos), e o adenocarcinoma, tipo mais raro e que acomete o epitélio glandular (cerca de $10 \%$ dos casos). (...) É uma doença de desenvolvimento lento, que pode cursar sem sintomas em fase inicial e evoluir para quadros de sangramento vaginal intermitente ou após a relação sexual, secreção vaginal anormal e dor abdominal associada com queixas urinárias ou intestinais nos casos mais avançados ${ }^{1}$.

O câncer de colo do útero, também chamado de câncer cervical, é o quarto tipo de câncer mais comum entre as mulheres no ranking nacional. Esse tumor é um dos tumores que apresenta maior potencial de prevenção e cura quando diagnosticado precocemente $^{2}$. No Brasil, em 2013, ocorreram 5.430 óbitos por câncer de colo uterino. $O$ câncer do colo do útero é raro em mulheres até 30 anos e o pico de sua incidência se dá na faixa etária de 45 a 50 anos¹.

Considerar uma boa cobertura no rastreamento da população alvo é uma estratégia de extrema importância para reduzir os índices de mortalidade por câncer de colo uterino. Um dado preocupante é que aproximadamente 12 a $20 \%$ das mulheres brasileiras na faixa etária preconizada (entre 25 e 64 anos que tenham atividade sexual) nunca realizou o exame de Papanicolau, lembrando que se os dois primeiros exames tiverem resultados normais, passa-se a fazer o rastreamento a cada três anos².

É importante atentar para as causas que diminuem a eficácia da cobertura no rastreio desta neoplasia, dentre estas, a acessibilidade e o acolhimento ofertados pelos serviços de saúde, tanto pela inflexibilidade de horários das equipes, que em sua grande maioria não está adequada para a realidade das mulheres, quanto por não acolher suas particularidades ${ }^{2}$.

O despreparo dos profissionais que realizam o acolhimento ao se deparar com aspectos étnicos, raciais, sociais e de gênero faz com que estes grupos de mulheres se afastem dos serviços de saúde ${ }^{2}$.

Respeitar as particularidades e indicações relacionadas a forma de como será realizado o exame, em condições como a gestação, por exemplo, que implica na não coleta da endocérvice, outro exemplo é a faixa etária não preconizada pelo Ministério da Saúde o que evita o rastreamento em mulheres cujo não haja necessidade, impedindo intervenções desnecessárias, tornando o cuidado efetivo e sendo primordial para a qualidade da assistência prestada ${ }^{2}$. 
A Atenção Básica, em especial a Estratégia Saúde da Família (ESF), é peça fundamental no rastreamento e monitoramento da população adscrita, por meio da realização de busca ativa e intervenções de educação em saúde sobre essas mulheres, impactando positivamente na redução da morbimortalidade por essa doença ${ }^{2}$.

É atribuição das equipes da ESF na Atenção Básica, prestar cuidado integral e a detecção precoce do câncer de colo de útero, além do acompanhamento terapêutico das mulheres nos demais níveis de atenção, quando existe algum resultado de exame de Papanicolaou alterado².

Além disso, permeando o contexto da ESF, há o atendimento à demanda espontânea, que objetiva receber o usuário que não tem nenhum tipo de atendimento agendado, mas que tem alguma queixa (problema) e que procura a Unidade Básica de Saúde para buscar resolutividade do mesmo. Este processo está inteiramente relacionado com a escuta qualificada e com o acolhimento que pode ser realizado por qualquer profissional da equipe de saúde. Em geral, é feito pelo profissional que está na recepção, é de suma importância que esta atitude seja efetiva e realizada de forma que estabeleça um vínculo de confiança entre usuário e serviço.

O acolhimento, como ação da ESF pode ser entendido não somente como um espaço ou local, mas sim como uma postura ética, uma vez que,

Não pressupõe hora ou profissional específico para fazê-lo, implica compartilhamento de saberes, angústias e invenções, tomando para si a responsabilidade de "abrigar e agasalhar" outrem em suas demandas, com responsabilidade e resolutividade sinalizada pelo caso em questão. Desse modo é que o diferenciamos de triagem, pois ele não se constitui como uma etapa do processo, mas como ação que deve ocorrer em todos os locais e momentos do serviço de saúde 3 .

Ainda, no que se refere ao acolhimento, é importante destacar que:

O acolhimento é um modo de operar os processos de trabalho em saúde, de forma a atender a todos que procuram os serviços de saúde, ouvindo seus pedidos e assumindo no serviço uma postura capaz de acolher, escutar e dar respostas mais adequadas aos usuários. Ou seja, requer prestar um atendimento com resolutividade e responsabilização, orientando, quando for o caso, o paciente e a família em relação a outros serviços de saúde, para a continuidade da assistência, e estabelecendo articulações com esses serviços, para garantir a eficácia desses encaminhamentos ${ }^{3}$.

A ideia de estudar sobre a relevância do acolhimento para as mulheres que farão o exame Papanicolaou surgiu a partir de uma demanda expressiva observada durante a anamnese, pelas enfermeiras que realizam este exame na unidade cenário, 
identificando-se que a grande maioria das mulheres que relatam já ter realizado este exame, não se sentiram a vontade com a conduta do profissional. São exemplos disso à falta de esclarecimento sobre o exame, além da forma de abordagem com as usuárias. Tendo em vista que esse exame é de extrema importância e que ele deve ser realizado anualmente até que se obtenham dois resultados sem alterações consecultivos, supõe-se que parte da motivação da mulher para retornar à Unidade Básica de Saúde (UBS) e realizar novo exame dependerá da forma como ela for acolhida. Outro fator a considerar é que a abordagem deste tema está relacionada com a vivência de um profissional enfermeiro da Residência Multiprofissional em Saúde da Família e Comunidade (RMSFC), nas ações de acolhimento e coleta de exame Papanicolaou, na unidade cenário. Assim, justifica-se estudar e apresentar resultados mediante o tema proposto, visando modificar positivamente a realidade da prática dos processos envolvidos na realização deste exame, contribuindo para uma assistência de enfermagem de melhor qualidade, junto à mulher usuária do serviço.

Este estudo teve como objetivo geral, identificar a influência do acolhimento em usuárias de uma unidade básica de saúde, relacionando-o ao seu retorno para coleta de exame de Papanicolaou, realizado por enfermeiros. Os objetivos específicos foram identificar a participação das usuárias no processo de acolhimento em consultas anteriores, para realização de exame Papanicolaou; conhecer os motivos que levaram a usuária a retornar para fazer o exame, e levantar sugestões, junto às usuárias atendidas, em relação a fatores que possam facilitar a adesão das mulheres no que se refere ao exame Papanicolaou. A pergunta de pesquisa buscou responder qual a influência do acolhimento, frente à realização do exame Papanicolaou pelo enfermeiro, para que as usuárias de uma Unidade Básica de Saúde retornem para os próximos exames?

\section{REVISÃO DE LITERATURA}

Considerando as premissas do Sistema Único de Saúde (SUS), sabe-se que na área da Atenção Básica, há uma equipe multiprofissional que deve desenvolver ações no nível de promoção da saúde dos usuários. Nessa esquipe e nesse estudo, chama-se a atenção para o profissional enfermeiro, destacando inicialmente o seu papel no contexto da estratégia de saúde da família, sendo que: 
O enfermeiro tem na prática desenvolvida em unidades básicas de saúde (UBS) o desafio de implementar o cuidado em enfermagem na construção de relações interpessoais de diálogo, escuta, humanização e respeito. Esta prática perpassa, portanto, pela compreensão do enfermeiro sobre o significado do seu fazer profissional, ou seja, do praticar o cuidado de enfermagem na atenção básica em saúde (ABS) ${ }^{4}$.

Ainda, de acordo com o afirmado na Política Nacional de Atenção Básica ${ }^{5}$, são atribuições do enfermeiro:

I - Realizar atenção à saúde aos indivíduos e famílias cadastradas nas equipes e, quando indicado ou necessário, no domicílio e/ou nos demais espaços comunitários (escolas, associações etc.), em todas as fases do desenvolvimento humano: infância, adolescência, idade adulta e terceira idade;

II - Realizar consulta de enfermagem, procedimentos, atividades em grupo e conforme protocolos ou outras normativas técnicas estabelecidas pelo gestor federal, estadual, municipal ou do Distrito Federal, observadas as disposições legais da profissão, solicitar exames complementares, prescrever medicações e encaminhar, quando necessário, usuários a outros serviços; III - Realizar atividades programadas e de atenção à demanda espontânea; IV - Planejar, gerenciar e avaliar as ações desenvolvidas pelos ACS em conjunto com os outros membros da equipe;

V - Contribuir, participar e realizar atividades de educação permanente da equipe de enfermagem e outros membros da equipe; e

$\mathrm{VI}$ - Participar do gerenciamento dos insumos necessários para o adequado funcionamento da UBS 5 .

Dentre as diversas frentes de atuação do profissional de enfermagem na atenção básica em saúde, é uma de suas atribuições a realização da coleta do exame citopatológico para câncer de colo de útero, conhecido como exame Papanicolaou. Tal exame deve ser realizado em mulheres, prioritariamente as que estão em atividade sexual, visando identificar doenças e principalmente o câncer de colo de útero o qual acomete milhares de mulheres. É uma doença silenciosa e trata-se de uma grande preocupação do setor de saúde. Por se tratar de um exame íntimo é de suma importância que o profissional esteja preparado para acolher as usuárias que procuram este atendimento. Nessa perspectiva, o acolhimento deve ocorrer desde 0 momento em que a usuária chega à UBS até o momento final da coleta, para que seja efetivada a criação de um vínculo e garantir a continuidade da assistência.

No ano de 2003 foi lançada a Política Nacional de Humanização (PNH), que trouxe uma nova forma de gerir e executar as diversas esferas do Sistema Único de Saúde (SUS), estando relacionada diretamente com o estímulo entre gestores, profissionais e usuários que fazem parte desse Sistema.

Os fundamentos da PNAB possuem um alinhamento conceitual muito articulado com as bases da Política Nacional de Humanização (PNH). Segundo a PNH, a humanização compreende: a valorização dos diferentes 
sujeitos implicados na produção de saúde; o fomento da autonomia e do protagonismo dos sujeitos e do coletivo; o aumento do grau de corresponsabilidade na produção da saúde e de sujeitos; o estabelecimento de vínculos solidários e de participação coletiva no processo de gestão; a identificação das necessidades sociais de saúde; o compromisso com a ambiência e com a melhoria do atendimento e condições de trabalho e cuidado, a constituição de vínculos solidários, a identificação das necessidades sociais e organização do serviço em função delas, entre outras 5 .

Neste sentido, iniciaram-se algumas práticas que vieram para melhorar os atendimentos aos usuários, como por exemplo, o acolhimento.

Acolher é reconhecer o que o outro traz como legítima e singular necessidade de saúde. $O$ acolhimento deve comparecer e sustentar a relação entre equipes/serviços e usuários/ populações. Como valor das práticas de saúde, o acolhimento é construído de forma coletiva, a partir da análise dos processos de trabalho e tem como objetivo a construção de relações de confiança, compromisso e vínculo entre as equipes/serviços, trabalhador/equipes e usuário com sua rede socioafetiva ${ }^{6}$.

Inerente à tríade coleta do exame Papanicolaou, atuação do enfermeiro e o acolhimento, propõem-se que na prática estes conceitos estejam intimamente relacionados e que se tornem presentes na atenção prestada às usuárias que acessam o atendimento de saúde através da Unidade Básica.

Isso é um grande desafio a ser superado no cotidiano dos profissionais, que na maioria das vezes são engolidos por uma demanda exagerada e que acabam deixando para trás alguns fragmentos que constituem este amplo contexto citado.

\section{MÉTODO}

Estudo de caráter explicativo com abordagem qualitativa, desenvolvido por meio de pesquisa ação.

O cenário da pesquisa foi uma Unidade de Saúde localizada em um bairro de uma cidade na serra catarinense, organizada com duas equipes de Estratégia de Saúde da Família, que atendem uma população de 7.167 pessoas, sendo destas 2.130 mulheres maiores de 18 anos $^{7}$.

Participaram desta pesquisa onze sujeitos, que estavam compatíveis com os critérios de inclusão e que procuram o serviço no mês de julho de 2017; não foram excluídos nenhum sujeito.

As entrevistas foram realizadas no mês de julho de 2017 , no período anterior e posterior a coleta do exame de Papanicolaou, tendo uma duração média de 30 
minutos. Os dados foram registrados no formulário de pesquisa (questionário), aplicado pela pesquisadora. Os sujeitos responderam o questionário em dois momentos; o primeiro, no inicio da consulta, com dados referentes à última coleta de Papanicolaou realizada por ele. Na sequência, foi realizado a coleta do exame Papanicolaou pela pesquisadora, de forma padrão, atendendo às questões burocráticas necessárias, como o preenchimento do Sistema de Informação do Câncer (SISCAN). Ao final da coleta, houve o segundo momento de resposta do questionário pelos sujeitos, tendo questões voltadas para a coleta atual.

A participação dos sujeitos no estudo foi voluntária, havendo concordância na participação pela assinatura do Termo de Consentimento Livre e Esclarecido (TCLE). A pesquisa seguiu os princípios e diretrizes estabelecidos na Resolução n־466/2012 do Conselho Nacional de Saúde (CNS). O estudo foi submetido a analise do Comitê de Ética em Pesquisa (CEP) da Universidade do Planalto Catarinense (UNIPLAC), tendo sido aprovado pelo parecer no 2.122 .028 datado de 15/06/2017. Os sujeitos tiveram seu anonimato respeitado, sendo identificados nos resultados por meio de números ordinais.

A análise qualitativa ocorreu seguindo o disposto no método hermenêuticodialético, proposto por Minayo ${ }^{8}$, sendo realizada a classificação das respostas obtidas, a partir de três etapas. A primeira etapa compreendeu a ordenação dos dados, quando se fez o mapeamento dos dados obtidos no trabalho de campo, através da leitura e releitura dos questionários organizando os relatos obtidos. A segunda etapa referiu-se à classificação dos dados obtidos no momento da ordenação, tendo sido identificado as relevâncias das respostas e, a partir disso foram criadas três categorias. A terceira etapa, constitui-se na análise final, quando foram articulados os dados obtidos com os referenciais teóricos da pesquisa.

\section{RESULTADOS E ANÁLISE}

A análise de dados pautou-se na proposta de $\mathrm{Minayo}^{8}$, e foi realizada através de classificação das respostas obtidas por meio de um questionário composto de duas etapas. A primeira etapa foi relativa aos antecedentes dos sujeitos, frente à coleta de exame de Papanicolaou e, a segunda etapa, relativa à coleta atual, a qual foi realizada pela pesquisadora. 
$\mathrm{Na}$ fase de interpretação, foi possível levantar o perfil dos sujeitos. Na fase exploratória foram elencadas categorias gerais descritivas dos aspectos relacionados ao acolhimento e que influenciam os sujeitos a retornarem à unidade básica de saúde para a coleta de exame de Papanicolaou. Após essa etapa, já no segundo nível de interpretação, foram elencadas três categorias de análise, baseadas nos achados primários da investigação, sendo: (a) Exame de Papanicolaou: perfil dos sujeitos; (b) Acolhimento: olhando para as necessidades de saúde (c) Acolhimento: a organização do serviço; as quais passam a ser apresentadas.

\section{Categoria (a): Exame de Papanicolaou - Perfil dos sujeitos}

Esta categoria apresenta o perfil dos sujeitos da pesquisa, expondo dados referentes à faixa etária, ao nível de escolaridade, ao histórico gestacional, aos antecedentes cirúrgicos ginecológicos, aos casos de câncer de mama e útero na família, sobre a data da última coleta e o resultado do último exame de Papanicolaou.

A faixa etária dos sujeitos variou entre 18 e 58 anos, estando a maioria entre 28 e 38 anos. $O$ grau de escolaridade foi a partir de $5^{\circ}$ ano do ensino fundamental até o nível técnico, sendo cinco sujeitos com ensino médio completo e um incompleto; dois com ensino fundamental completo e três incompleto.

Em relação aos dados do histórico gestacional houve uma variável de dois sujeitos que tiveram o número de gestações entre zero e um, seis sujeitos que tiveram entre duas e três gestações, dois sujeitos tiveram entre quatro e cinco gestações e um sujeito teve seis e sete gestações.

Referente aos tipos de parto identificou-se que, em relação a parto normal, quatro sujeitos que tiveram de zero a um, seis sujeitos tiveram entre dois e três, dois sujeitos tiveram quatro e cinco partos normais e entre seis e sete foram um sujeito. Para partos cesarianos identificou-se que foram nove sujeitos na escala de zero a um parto cesariano, entre dois e três partos cesáreos foram dois sujeitos e para as demais alternativas nenhum sujeito. Para abortos entre zero e um foram dez sujeitos e para entre dois e três abortos teve um sujeito.

Em se tratando de casos de câncer de mamas e útero na família, identificou-se que cinco dos sujeitos relataram este histórico, sendo dois por parte de mãe (mama), um por parte de primas (mama), um por parte de irmã (mama/útero) e um por parte de avó (mama); e, seis nunca tiveram estes casos na família. 
Sobre a realização de cirurgias ginecológicas prévias, sete dos sujeitos registraram que passaram por cirurgias de retirada de útero, cesariana, laqueadura e retirada de cistos dos ovários; os outros quatro sujeitos relataram que não tinham nenhum antecedente cirúrgico.

Quando questionados sobre a data da última coleta de exame, três sujeitos registraram ter realizado a coleta antes do ano de 2011; entre os anos de 2012 e 2013 houve um registro; nos anos de 2013 a 2014 nenhum registro e, entre os anos de 2015 a 2016 foram seis sujeitos que realizaram o exame. Houve um sujeito que não lembrava a data.

Sobre os últimos resultados do exame de Papanicolaou, sete dos sujeitos registraram como bom e dois como ruins, sendo deste um infecção/ferida e o outro alterado/infecção; dois não lembravam. Referente à intercorrências clínicas decorrentes do último exame um dos sujeitos registrou que houve um pequeno sangramento e os outros dez relataram que não houve.

Sobre esses achados pode-se identificar que, de um quantitativo de onze sujeitos, seis voltaram para realizar o exame com dois anos após a última coleta. Em relação ao nível de instrução dos sujeitos, considerando que a maioria tem algum tipo de formação educacional, entende-se que isso favoreceu a compreensão acerca do exame. Relativo ao número de gestações/ partos, registrou-se alto, pois a maioria teve de duas a três gestações.

Relacionando os dados levantados com um estudo de caráter prático, que visou promover educação em saúde sexual e conhecer o perfil da saúde sexual de mulheres de Santo Ângelo/RS, apresentou como faixa estaria prevalente do grupo estudado entre 20 e 30 anos, sendo próxima aos resultados encontrados com a presente pesquisa, pois a faixa etária prevalente neste caso foi entre 28 a 38 anos 9 .

Ainda relativo a faixa etária, é importante atentar para o aumento da incidência desta doença nos grupos com idade compreendidas entre 20 e 30 anos, isso se dá principalmente pelo maior contato com agentes transmissores de infecções sexualmente transmissíveis e ao uso de métodos contraceptivos de barreira de forma incorreta ${ }^{9}$.

Casarin e Piccoli ${ }^{9}$ ainda destacam que, em relação ao nível de escolaridade das mulheres pesquisadas, o resultado aponta que a maioria tem nível superior. Comparando esse dado com resultados obtidos na pesquisa atual, pode-se observar 
que são resultados contrários, sendo que o nível de escolaridade entre a maioria dos sujeitos foi ensino médio completo.

Sobre o intervalo de tempo entre o último exame e o atual, os achados de Casarin e Piccoli ${ }^{9}$ indicaram que a maioria das mulheres havia realizado no último ano/ anterior a pesquisa. Isso se assemelha aos resultados obtidos nesta pesquisa, sendo que seis dos sujeitos realizou o último exame entre os anos de 2015 e 2016.

Ainda nesta relação de achados, considerando os resultados relacionados à história familiar de câncer do colo uterino na família da pesquisa de Casarin e Piccoli ${ }^{9}$, observou-se que houve a presença de treze relatos positivos, sendo que as demais negaram ou desconheciam sua história familiar. Considerando o grau de parentesco mais afetado foi o de mães e tias, seguido de irmãs, com duas citações e primas e avós. Num comparativo com os achados desta pesquisa cinco sujeitos relataram histórico para câncer de mama e útero na família, destes cinco apenas um era de útero do grau de parentesco de irmã, os outros quatro são de mamas, com grau de parentesco de mãe, avó e prima.

\section{Categoria (b): Acolhimento - olhando para as necessidades de saúde}

Considerando que a prática do acolhimento pauta-se na escuta das demandas do usuário, possibilitando ao profissional de saúde identificá-las e dar respostas às mesmas, esta categoria apontou aspectos relevantes e positivos para o acolhimento.

Num comparativo entre os dados relativos à consulta anterior e a realizada pela pesquisadora foram identificados aspectos referentes aos sentimentos dos sujeitos durante a coleta, ao espaço para retirada de dúvidas, sobre desconfortos físicos no momento do exame, sobre a realização de exame de mamas, sobre os motivos para retorno à coleta do exame Papanicolaou e também o aspecto educativo no ato do exame, os quais passam a ser descritos.

Em relação ao sentimento de bem-estar dos sujeitos durante a primeira coleta, houve relatos de nove sujeitos que foi tudo bem, mas também um sujeito relatou que sentiu desconfortável e um que não lembra. Na coleta atual os onze sujeitos responderam que se sentiram bem, tendo destaque nas seguintes falas:

"Bem confortável" (Sujeito 02).

"Bem tranquila” (Sujeito 04).

"Muito bem" (Sujeito 08). 
Em relação à existência de alguma diferença entre as coletas anteriores frente à coleta atual de Papanicolaou, nove dos sujeitos disseram que foi melhor a atual $\mathrm{e}$ dois sujeitos responderam que não houve diferença, isso se se evidencia nas seguintes respostas:

"Sim, melhor foi com mais atenção e explicação" (Sujeito 03). "Sim, bem mais leve, quase não senti fazer" (Sujeito 04).

"Bastante, foi grande a mudança para melhor, os materiais descartáveis, mais confiante" (Sujeito 08). "Sim, foram bem acolhedoras" (Sujeito 10).

Sobre a existência de um espaço para tirar dúvidas, na primeira coleta isso não foi identificado por parte de seis sujeitos, os outros cinco sujeitos relataram que este espaço foi ofertado; e, na segunda coleta identificou-se esse espaço nos relatos de ter havido um sentimento de segurança, quando os sujeitos o relacionam ao fato de terem recebido melhor esclarecimento sobre o procedimento, deixando-as confiantes, conforme o seguinte relato,

"Sim, foi esclarecido" (Sujeito 09).

Além disso, foi pontuado uma diferença ou aspecto positivo na segunda coleta, relacionado ao fato do recebimento de orientações por parte da pesquisadora, referentes ao procedimento a ser realizado, sobre a importância do mesmo e o fato de ter sido demonstrado previamente o material a ser utilizado no momento do exame.

Sobre desconfortos físicos no momento do exame, na primeira coleta não foram registrados e na segunda foram praticamente inexistentes; isso se confirma pelo relato dos sujeitos que, o fato da pesquisadora ter se preocupado em orientá-la e reposicioná-la durante a coleta para melhor visualização do colo, facilitando a realização do exame, o que se destaca na fala,

"Sim, teve reposicionamento para facilitar a coleta" (Sujeito 09).

Outro aspecto foi sobre a realização do exame de mamas, sendo que, na primeira consulta não foi realizado em quatro dos sujeitos, nos outros sete sujeitos o 
exame foi realizado. Na consulta atual o exame de mamas foi realizado em nove dos sujeitos, nos outros dois, o exame não foi realizado por respeito à opção do sujeito.

Sobre os motivos para retorno à coleta do exame Papanicolaou, na primeira consulta seis sujeitos relataram que, o que os fez retornar foi à consciência sobre a rotina da coleta e prevenção de possível doença, um dos sujeitos relatou que foi por recomendação médica e três disseram que foram por sintomas relacionados a questões ginecológicas, como cólicas, dor na relação sexual e etc. Na segunda coleta, quando questionados se voltariam para realizar o exame houve uma unanimidade sendo que, os onze sujeitos responderam que sim. Questionados sobre os motivos registrados para retorno apontaram o bom atendimento da pesquisadora, o fator de prevenção à saúde e a rotina da coleta e, pela necessidade que possa surgir. Tais questões se traduzem nas seguintes falas:

"Sim, porque fui bem atendida e tive bastante explicação" (Sujeito 03). "Sim, pela mudança que houve, atendimento" (Sujeito 08). "Sim, porque fui bem acolhida" (Sujeito 10). "Sim, porque não foi difícil e é benéfico para mim" (Sujeito 11).

Sobre o aspecto educativo relacionado a compreensão dos sujeitos, prévia e posterior ao exame, identificou-se que houve uma melhora no entendimento do processo, sendo que, quando questionados sobre se o esclarecimento acerca do exame era o mesmo orientação da pesquisadora, oito sujeitos responderam que mudou, pois aprenderam mais e, os outros três sujeitos relataram que mantiveram a compreensão já existente, o que pode ser observado nas seguintes falas:

"Não, aprendi um pouco mais" (Sujeito 06).

"Hoje não, entendo que é necessário" (Sujeito 10). "Não, mudou para melhor, ficou a par realmente de como é feito o exame" (Sujeito 11).

Realizando a análise dos achados de modo comparativo, observou-se que os dados obtidos na primeira parte do questionário com os da segunda parte apontaram pontos positivos na coleta atual, uma vez que os sujeitos relataram que não havia sido realizada entrevista na última coleta, que não foi proporcionado espaço para tirar dúvidas e que não foi realizado o exame de mamas. 
Ainda frente aos aspectos positivos relacionados à prática do acolhimento dos usuários nas UBSs há que se pensar a maneira como esse é efetivado. De acordo com Brasil $^{2}$, as reflexões sobre o processo de acolhimento remetem ao próprio sentido da palavra, aos significados que ela traz à ideia de acolher, ouvir, receber, aproximar, estar em relação com algo ou alguém.

Compreende-se que a relação do acolhimento com a realização do exame Papanicolaou é extremamente próxima, o que corrobora com alguns estudos já realizados e que trazem em seus resultados um destaque para o vínculo estabelecido entre profissional e usuária.

O vínculo, sem dúvidas é fator preponderante para favorecer o processo de retorno das usuárias ao serviço, bem como para tonar efetivas as ações de educação em saúde realizadas durante a coleta de Papanicolaou.

Em um estudo realizado por Peretto, Drehmer e Bello ${ }^{10}$, observou-se que o estabelecimento de vínculo facilita a exposição dos sentimentos e experiências por parte da usuária que são protagonistas neste contexto, o que vem ao encontro dos achados nesta pesquisa. Através do estabelecimento deste vínculo o profissional se coloca em uma postura com a presença de empatia e sensibilidade que agregadas ao conhecimento técnico-científico irão resultar em uma relação de confiança e sucesso. Ainda neste processo é possível promover o esclarecimento das questões que estão ligadas ao conhecimento do corpo e também dos aspectos psicossociais envolvidos, buscando ainda desconstruir paradigmas que estão intimamente relacionados à sexualidade, sendo que esta é uma das principais causas que dificultam a realização deste exame. É imprescindível que o profissional seja um educador que incentiva às usuárias para este exame e que promova a participação e a co-responsabilização pela saúde das mesmas. Consequentemente ocorrerá a minimização de sentimentos como vergonha e ansiedade ${ }^{10}$.

Em relação ao sentimento de bem-estar dos sujeitos durante a primeira coleta, mais uma vez o vinculo aparece como facilitador. Isso se traduz no estudo de Ressel, Stumm, Rodrigues, Santos e Junges ${ }^{11}$, quando apontou que há a necessidade do profissional compreender a mulher em sua integralidade considerando aspectos sociais, culturais e econômicos, propiciando um acolhimento humanizado. A partir do momento que se estabelece um vínculo consegue-se reduzir os sentimentos ruins e assegura-se que esta mulher retorne para um novo atendimento e dessa vez menos preocupada e envergonhada. Outra questão a ser destacada é toda a preparação para 
este exame que deve ser exercida pelo profissional com o objetivo de trazer bem-estar à mulher ${ }^{11}$.

Os achados desta pesquisa revelaram que os motivos para retorno à coleta do exame Papanicolaou, foram variados, apontando para questões ginecológicas, solicitação médica e pela rotina de prevenção. Isso corrobora com estudo de Casarin e Piccoli9, que apontam como motivos de procura do exame existência de dor abdominal, sangramento após as relações sexuais, menstruações irregulares, solicitação de algum médico, presença de leucorréia e medo, por terem familiares, amigas, vizinhas, que tiveram a doença.

\section{Categoria (c): Acolhimento - a organização do serviço}

Nessa categoria são apresentados os dados referentes a organização do serviço, que envolvem o espaço físico/ sala de coleta, os materiais utilizados na coleta do exame e o processo de trabalho desenvolvido, caracterizados pelo atendimento e os motivos de retorno à coleta.

Sabe-se que a compreensão de acolhimento é absolutamente mais ampla do que sua dimensão espacial, porém, sabe-se também que os aspectos relacionados ao ambiente, como conforto e segurança, são fundamentais para 0 bom desenvolvimento dos processos assistenciais, especialmente quando se trata de um exame íntimo como o de Papanicolaou.

Em relação ao local, ambiente físico/sala de coleta, todos os onze os sujeitos apontaram como bom na primeira coleta, já na segunda coleta dez dos sujeitos registraram como bom e um fez algumas ponderações que apontam aspectos tanto positivos e negativos, destaque para os seguintes relatos:

"Sim, tudo ótimo" (Sujeito 04).

"Bem melhor do que era antigamente" (Sujeito 08).

"Seguro, sigiloso, porém pequeno e inadequado, higiene do banheiro poderia melhorar" (Sujeito 09).

Em relação aos materiais utilizados na coleta do exame, tanto na coleta anterior como na atual, os sujeitos apontaram que estavam adequados.

Tais achados corroboram com a ideia de que a potencialidade do estabelecimento de um vínculo profissional-usuário e do acolhimento como principal 
ferramenta vai além da necessidade de grandes estruturas para a efetivação de um atendimento humanizado e integral, o que se traduz em tecnologias leves.

Sobre os motivos para retorno à coleta do exame Papanicolaou, na primeira consulta seis sujeitos relataram que, o que os fez retornar foi à consciência sobre a rotina da coleta e prevenção de possível doença, um dos sujeitos relatou que foi por recomendação médica e três disseram que foram por sintomas relacionados a questões ginecológicas, como cólicas, dor na relação sexual e etc. Na segunda coleta, quando questionados se voltariam para realizar o exame houve uma unanimidade sendo que, os onze sujeitos responderam que sim. Questionados sobre os motivos registrados para retorno apontaram o bom atendimento da pesquisadora, o fator de prevenção à saúde e a rotina da coleta e, pela necessidade que possa surgir. Tais questões se traduzem nas seguintes falas:

"Sim, porque fui bem atendida e tive bastante explicação" (Sujeito 03). "Sim, pela mudança que houve, atendimento" (Sujeito 08). "Sim, porque fui bem acolhida" (Sujeito 10). "Sim, porque não foi difícil e é benéfico para mim" (Sujeito 11).

Referente a sugestões dois sujeitos deixaram registrado o que poderia melhorar e os outros nove sujeitos responderam que não há o que melhorar, como exemplo disso podemos citar:

"Já melhorou muito, bem significativo, melhora na entrega do resultado" (Sujeito

"O local" (Sujeito 09).

"O ambiente acolhedor, a conversa como estão fazendo" (Sujeito 10).

"Se for como foi hoje, seria perfeito" (Sujeito 11).

Frente aos achados, pode-se compreender que o acolhimento vai muito além de um espaço físico, traz no seu escopo uma forte ligação com o estabelecimento de vínculo entre profissional e usuário, não necessitando de recursos tecnológicos ou materiais sofisticados e sim de tecnologias leves como a escuta qualificada.

Além disso, o acolhimento possibilita ser agente transformador de mudanças, pois propicia aos trabalhadores instrumentalizar o processo de trabalho e viabilizar uma avaliação do mesmo ${ }^{12}$. 


\section{CONSIDERAÇÕES FINAIS}

Este estudo se propôs identificar a influência do acolhimento em usuárias de uma unidade básica de saúde, relacionando-o ao seu retorno para coleta de exame de Papanicolaou, realizado por enfermeiros.

No primeiro momento foi evidenciado que os motivos que levaram os sujeitos a virem realizar o exame Papanicolaou foram questões ginecológicas, rotina de prevenção e cuidado consigo mesma ou por solicitação médica, o que não se relaciona diretamente com a criação anterior de vínculo com profissionais ou com a realização de um acolhimento efetivo.

Isso se contrapõe com os dados levantados no período após a realização do exame atual, pela pesquisadora, quando os sujeitos foram questionados se retornariam para uma nova coleta de Papanicolaou. As respostas evidenciaram relatos positivos para o retorno, associados à forma como foram acolhidas, ao sentimento de segurança estabelecido, o qual minimizou os sentimentos ruins que poderiam estar presentes durante o exame. $O$ fator segurança foi associado a ações como a demonstração do material a ser utilizado no exame e a conversa estabelecida para efetivação da educação em saúde, entre pesquisadora e usuária.

Além disso, o espaço aberto para conhecer as sugestões dos sujeitos para melhorar a qualidade da prática do exame Papanicolaou, foi de extrema relevância, pois permitiu conhecer a percepção dos mesmos. Sobre isso, destaca-se que a única sugestão apontada pelos sujeitos está relacionada ao ambiente físico, sala de coleta, e não ao processo de trabalho e atendimento em si. Isso corrobora com a ideia de que não é necessário dispor de grandes tecnologias para efetivar um cuidado integral e humanizado, muito pelo contrário, ressalta novamente que o estabelecimento de um vínculo entre profissional e usuário consegue superar as adversidades encontradas e que na grande maioria das vezes estão fora de nosso alcance resolvê-las.

Posto isso, entende-se que o objetivo foi alcançado, pois compreende-se que o acolhimento está imposto na postura que o profissional adota em sua prática, sendo a efetivação do cuidado que perpassa desde o início do atendimento até o fim do procedimento.

Esta postura profissional embebida dos princípios do acolhimento tem impacto na qualidade de vida das usuárias, fazendo-as terem confiança na realização deste exame de extrema importância para prevenção de câncer de colo do útero. 
O acolhimento está se difundindo cada vez mais no cenário da saúde e os resultados obtidos com esta prática vão além de um bom atendimento que garante o retorno do usuário para um novo atendimento, mas sim está relacionado com educação em saúde, resolutividade, desmistificações de tabus enraizados culturalmente, carregando os princípios do SUS garantindo o acesso equânime, humanizado e universal efetivando com qualidade $o$ atendimento.

É importante deixar claro que manter a prática do acolhimento é um desafio cotidiano para os profissionais de saúde, pois requer a real efetivação do trabalho em equipe e uma gestão co-participativa que invista em educação permanente, refletida na qualificação dos profissionais e dos serviços.

\section{REFERÊNCIAS}

1- Controle do Câncer do Colo de Útero [internet]. Rio de Janeiro: Instituto Nacional do Câncer - INCA. [Acesso em: 2016 set. 05]. Disponível em: http://www2.inca.gov.br/wps/wcm/connect/acoes programas/site/home/nobrasil/prog rama nacional controle cancer colo utero/conceito magnitude.

2- Ministério da Saúde. Instituto Sírio-Libanês de Ensino e Pesquisa. Protocolos da Atenção Básica: Saúde das Mulheres. Brasília: Ministério da Saúde; 2016.

3- $\quad$ Ministério da Saúde. Secretaria de Atenção à Saúde. Acolhimento nas práticas de produção de saúde. Brasília: Ministério da Saúde, 2010.

4- Acioli S, Kebian LVA, Faria MGA, Ferraccioli P, Correa VAF. Práticas de cuidado: o papel do enfermeiro na atenção básica. Rev. Enferm. UERJ. 2014; 22(5): 637-42. Doi: http://dx.doi.org/10.12957/reuerj.2014.12338

5- $\quad$ Ministério da Saúde. Secretaria de Atenção à Saúde. Política Nacional de Atenção Básica. Brasília: Ministério da Saúde, 2012.

6- Ministério da Saúde. Secretaria de Atenção à Saúde. Política Nacional de Humanização. Brasília: Editora Premium, 2015.

7- $\quad$ Relatório G-MUS [Internet]. Lages: Secretaria Municipal de Saúde de Lages. 2017; [Acesso em: 2017 mai. 03]. Disponível em: 172.20.160.8:webgemus_lages_utf8.

8- Minayo, MCS. Pesquisa social: teoria, método e criatividade. 23.ed. Petrópolis: Editora Vozes, 2004.

9- $\quad$ Casarin MR, Piccoli JCE. Educação em saúde para prevenção do câncer de colo do útero em mulheres do município de Santo Ângelo/RS. Rev. Ciência \& Saúde Coletiva. 2011; 16(9): 3925-32. Doi: http://dx.doi.org/10.1590/S141381232011001000029.

10- Peretto M, Drehmer LBR, Bello HMR. O não comparecimento ao exame preventivo do câncer de colo Uterino: razões declaradas e sentimentos envolvidos. Rev. Cogitare Enferm. 2012; 17(1): 29-36. Doi: http://dx.doi.org/10.5380/ce.v17i1.26371.

11- Ressel LB, Stumm KE, Rodrigues AP, Santos CC, Junges CF. Exame preventivo do câncer de colo uterino: a percepção das mulheres. Rev. Avances en 
enfermeira. 2013; 31(2): 65-73. [Acesso em: 2017 set. 12]. Disponível em: http://www.scielo.org.co/pdf/aven/v31n2/v31n2a07.pdf.

12- BARRA, S. O acolhimento no processo de trabalho em saúde. Rev. Serv. Soc. Rev. 2011; 13(2): 119-42. [Acesso em: 2017 nov. 08]. Disponível em: http://www.facenf.ueri.br/v22n5/v22n5a09.pdf. 